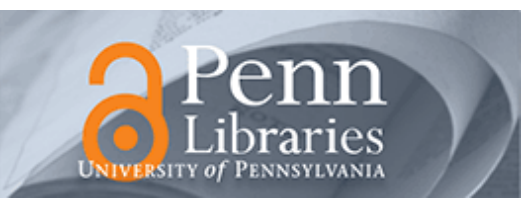

University of Pennsylvania

ScholarlyCommons

September 2005

\title{
Using Palm Technology in Participatory Simulations of Complex Systems: A New Take on Ubiquitous and Accessible Mobile Computing
}

Eric Klopfer

Massachusetts Institute of Technology

Susan A. Yoon

University of Pennsylvania, yoonsa@gse.upenn.edu

Judy Perry

Massachusetts Institute of Technology

Follow this and additional works at: https://repository.upenn.edu/gse_pubs

\section{Recommended Citation}

Klopfer, E., Yoon, S. A., \& Perry, J. (2005). Using Palm Technology in Participatory Simulations of Complex Systems: A New Take on Ubiquitous and Accessible Mobile Computing. Retrieved from

https://repository.upenn.edu/gse_pubs/54

Postprint version. Published in Journal of Science Education and Technology, Volume 14, Issue 3, September 2005, pages 285-297.

NOTE: At the time of publication, author Susan Yoon was affiliated with The Massachusetts Institute of Technology. Currently, March 2007, she is a faculty member of the Graduate School of Education at the University of Pennsylvania.

This paper is posted at ScholarlyCommons. https://repository.upenn.edu/gse_pubs/54

For more information, please contact repository@pobox.upenn.edu. 


\title{
Using Palm Technology in Participatory Simulations of Complex Systems: A New Take on Ubiquitous and Accessible Mobile Computing
}

\author{
Abstract \\ This paper reports on teachers' perceptions of the educational affordances of a handheld application \\ called Participatory Simulations. It presents evidence from five cases representing each of the \\ populations who work with these computational tools. Evidence across multiple data sources yield \\ similar results to previous research evaluations of handheld activities with respect to enhancing \\ motivation, engagement and self-directed learning. Three additional themes are discussed that provide \\ insight into understanding curricular applicability of Participatory Simulations that suggest a new take on \\ ubiquitous and accessible mobile computing. These themes generally point to the multiple layers of \\ social and cognitive flexibility intrinsic to their design: ease of adaptation to subject-matter content \\ knowledge and curricular integration; facility in attending to teacher-individualized goals; and encouraging \\ the adoption of learner-centered strategies.

\section{Keywords} \\ simulations, handhelds, complex systems

\section{Comments} \\ Postprint version. Published in Journal of Science Education and Technology, Volume 14, Issue 3, \\ September 2005, pages 285-297. \\ NOTE: At the time of publication, author Susan Yoon was affiliated with The Massachusetts Institute of \\ Technology. Currently, March 2007, she is a faculty member of the Graduate School of Education at the \\ University of Pennsylvania.
}




\title{
Using Palm Technology in Participatory Simulations of Complex Systems: A New Take on Ubiquitous and Accessible Mobile Computing
}

\author{
Eric Klopfer, ${ }^{1,2}$ Susan Yoon, ${ }^{1}$ and Judy Perry ${ }^{1}$
}

\begin{abstract}
This paper reports on teachers' perceptions of the educational affordances of a handheld application called Participatory Simulations. It presents evidence from five cases representing each of the populations who work with these computational tools. Evidence across multiple data sources yield similar results to previous research evaluations of handheld activities with respect to enhancing motivation, engagement and self-directed learning. Three additional themes are discussed that provide insight into understanding curricular applicability of Participatory Simulations that suggest a new take on ubiquitous and accessible mobile computing. These themes generally point to the multiple layers of social and cognitive flexibility intrinsic to their design: ease of adaptation to subject-matter content knowledge and curricular integration; facility in attending to teacher-individualized goals; and encouraging the adoption of learner-centered strategies.
\end{abstract}

\section{INTRODUCTION}

Since their introduction to the mass market slightly more than a decade and a half ago, handheld computer use has expanded well beyond their original "personal information management" functionality especially in educational circles. Teachers around the world are now capitalizing on the affordances these small, inexpensive, mobile tools can offer in a myriad of learning environments. They have been highly touted as the computing platform that can potentially address accessibility issues stemming from economic and structural barriers that make a $4: 1$ ratio of desktop computers to students in static self-contained "down-the-hall" computer labs a reality in schools (Soloway et al., 2001). Through embedded peer-to-peer communication capabilities such as infrared-enabled beaming, peripheral devices such as external keyboards and probes, and wireless internet connectivity, educational ap-

\footnotetext{
${ }^{1}$ Teacher Education Program, Massachusetts Institute of Technology, Cambridge, Massachusetts 02139-4307.

${ }^{2}$ To whom correspondence should be addressed; e-mail: klopfer@ mit.edu
}

plications for handhelds have been developed to enhance a diverse number of learning domains. These include scientific data collection and analysis (Bannasch and Tinker, 2002; Metcalf and Tinker, 2004; Tinker and Krajcik, 2001), word processing, language development and concept inscription (Curtis et al., 2002; Ogata and Yano, 2003), and topological representations in mathematics (Goldman et al., 2004; Roschelle and Pea, 2002).

Perhaps the greatest research emphasis, however, has been geared toward understanding the role of networked (centralized or peer-peer) handhelds in influencing core computer supported collaborative learning (CSCL) skills and abilities, e.g., communication and collaboration (Jipping et al., 2001; Ogata et al., 2001; Zurita and Nussbaum, 2004); decisionmaking (Relan et al., 2003; Woodruff et al., 2003; Yoon and Woodruff, 2003); personalization of understanding, motivation and engagement (Colella, 2000; Inkpen, 1999; Klopfer et al., 2004); assessment (Abrahamson et al., 1989) and information accessibility (Clyde, 2004; May, 2003).

Following on insights gleaned from the abovementioned studies and earlier work using MIT 
Thinking Tag/Badge technologies (Andrews et al., 2003; Borovoy et al., 1996; Colella, 2000; Klopfer and Woodruff, 2002; Yoon and Woodruff, 2003), over the last few years the educational technologies research team at the MIT Teacher Education Program has been developing Participatory Simulations for use on Palm OS computers. To date there are six applications and two additional ones in development.

\section{Evaluation of Learning Impacts}

Roschelle (2003, p. 264) suggests the learning value of Participatory Simulations may stem from students having "rich conceptual resources for reasoning about and thoughtfully acting in playful spaces, and thus can more easily become highly engaged in the subject matter." As the field of educational handhelds moves ahead at a rapid pace, however, evaluation of classroom impact has understandably lagged behind technological development. We are only now starting to map the costs and benefits onto learning outcomes as handheld activities are increasingly implemented in real educational settings. Some studies in classrooms using handhelds discuss teachers' perceptions of teaching and learning utilities. For example, in a year-long evaluation of the Palm Education Pioneer (PEP) program, Vahey and Crawford (2002, p. iii) conclude that of the $102 \mathrm{~K}-12$ classrooms surveyed, $90 \%$ of teachers believed that "handhelds are an effective instructional tool; that handhelds have the potential to have a positive impact on student's learning and that they will continue to use handhelds in the future." Key learning outcomes cited include increased motivation and selfdirectedness, accessibility and portability as a personal learning tool, and influence on collaboration and communication. Handheld use in those classrooms can be viewed as generally geared toward enhancing domain general knowledge and skills such as data collection, personal information management and language activity support such as improving writing processes.

The research presented in this paper differs from much of the previous studies in that the software has been designed to develop domain specific conceptual knowledge through handheld curricular innovations. As with previous studies, results show that these technologies enhance motivation and engagement in the classroom (Colella, 2000; Klopfer et al., 2004) and likewise corroborate claims of ubiquitous and accessible computational affordances (cf. Soloway et al., 2001). The purpose of this pa- per, however, is to identify issues, advantages and challenges in implementing Participatory Simulations from the educator's perspective and presents evidence to suggest an alternative interpretation of the ubiquity and accessibility theme. Given the wide range of educational groups who use these simulations, this exploration includes educators across multiple levels and disciplines. Specifically, this study reports on patterns found amongst five cases of Participatory Simulation use in which teachers' perceptions of the simulations, either after classroom implementation or as part of professional development training, were investigated. Two general goals have directed research efforts: (a) To determine ease of applicability in curricular contexts; and (b) To understand teachers' perceptions of the simulation activities both in terms of intended and actualized learning outcomes.

\section{METHODOLOGY}

\section{Participatory Simulations}

Foundational concepts underpinning the design and use of Participatory Simulations include (a) immersion of participants in simulations of complex phenomena; (b) development of inquiry and research design skills; (c) negotiation, coordination and alignment of individual local behavior in order to foster group-level systems understanding. The existing Participatory Simulations are briefly described in Table I (for a more detailed explanation or to download simulations, please visit: http://education.mit.edu/pda). As an outgrowth of the StarLogo computer-based modeling tool (Fig. 1; left panel) designed for desktop platforms (cf. Colella et al., 2001; Resnick, 1994), Participatory Simulations offer an additional perspective providing off-screen, first-person experience and insight into the dynamics and emergent behavior as students themselves become agents in a complex system (Fig. 1; right panel). Information and conceptual knowledge that circulates through peerto-peer interaction takes on different forms in each of the simulations, e.g., genetic/variability, predatorprey relationships, epidemiological infection rates, opinion change over time, factors affecting competition and cooperation and the dynamics of economic markets. The record of activity resulting from these interactions provide the raw data with which students investigate the underlying rules and build theories about how the encompassing system operates. In this regard, the Participatory Simulations 
Table I. List and Description of Participatory Simulations Developed at MIT

\begin{tabular}{|c|c|c|}
\hline Participatory simulation & Sample palm screen & Description \\
\hline Big Fish—Little Fish & 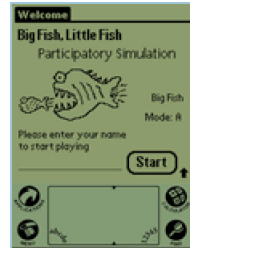 & $\begin{array}{l}\text { Big Fish-Little Fish (BFLF) models a predator prey system. Some } \\
\text { players are schools of big fish who need to eat little fish to survive, } \\
\text { while other players are schools of little fish who must avoid the big } \\
\text { fish to survive. Players can track their school size over time via } \\
\text { numerical readouts and real time graphs. The challenge is to support } \\
\text { as many fish as possible in the pond, and preserve species diversity. }\end{array}$ \\
\hline Discussion & 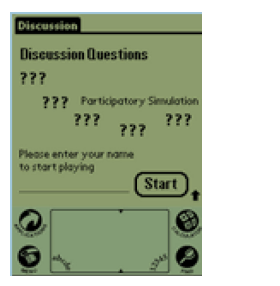 & $\begin{array}{l}\text { The Discussion simulation poses a statement to participants which they } \\
\text { must consider (e.g. "Technology has succeeded in changing } \\
\text { classroom practices"). Participants individually rate their agreement } \\
\text { or disagreement with the statement and provide a brief rationale. } \\
\text { Then everyone must go around and make their case to the other } \\
\text { players, and track how their own opinion and rationale changes in } \\
\text { response to feedback from others. }\end{array}$ \\
\hline Live Long and Prosper & 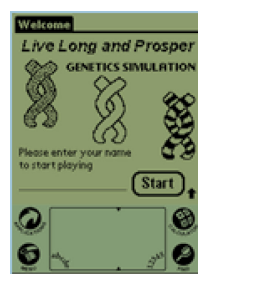 & $\begin{array}{l}\text { Live Long and Prosper (LLAP) is a genetics simulation. Players take } \\
\text { the role of an organism with a simple genome (between } 1 \text { and } 8 \\
\text { genes) that is represented on their screens. Players quickly age and } \\
\text { must produce offspring to survive. While players get points for } \\
\text { surviving and reproducing, the game quickly becomes about trying to } \\
\text { figure out what traits the genes code for. }\end{array}$ \\
\hline Tit for Tat (Prisoner's Dilemma) & 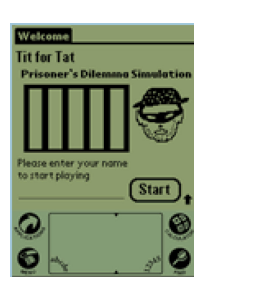 & $\begin{array}{l}\text { Tit for Tat is a fairly straightforward implementation of the problem of } \\
\text { the Prisoner's Dilemma. Players have the choice of cooperating with } \\
\text { or defecting against their partners to get points. While the "obvious" } \\
\text { choice seems to be defection the game can enforce multiple meetings, } \\
\text { small communities, and payoff changes that lead to the exploration of } \\
\text { the evolution of cooperation. }\end{array}$ \\
\hline Virus & 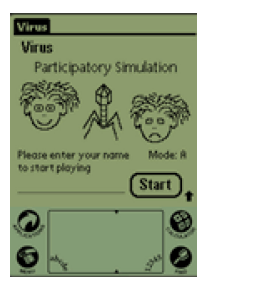 & $\begin{array}{l}\text { Virus is the game that started it all. Everyone in the game initially } \\
\text { appear to be healthy. Players are then given the task to meet as many } \\
\text { people as possible without getting sick. Just how do you do that? } \\
\text { That is what players must figure out. As the game proceeds some } \\
\text { players get sick. Play again to try to determine how the virus works. }\end{array}$ \\
\hline Sugar and Spice & (2) & $\begin{array}{l}\text { Sugar and Spice is a simple game of economics, loosely based on the } \\
\text { artificial societies of Epstein and Axtell's Growing Artificial Societies. } \\
\text { In this game sugar producers and spice producers must negotiate } \\
\text { trades in order to survive. Along the way players must try to learn } \\
\text { how the system works in order to optimize their trading strategies. }\end{array}$ \\
\hline
\end{tabular}

discussed in this study, in which learners interact solely through individual handhelds, are conceptually distinct from the Hubnet Participatory Simulations (Wilensky and Stroup, 2000) in which learners control individual agents that interact in a shared vir- tual environment. While both tools attempt to foster conceptual development in complex systems domains, the research investigated here, and many of the emergent themes relate specifically to our research program. 

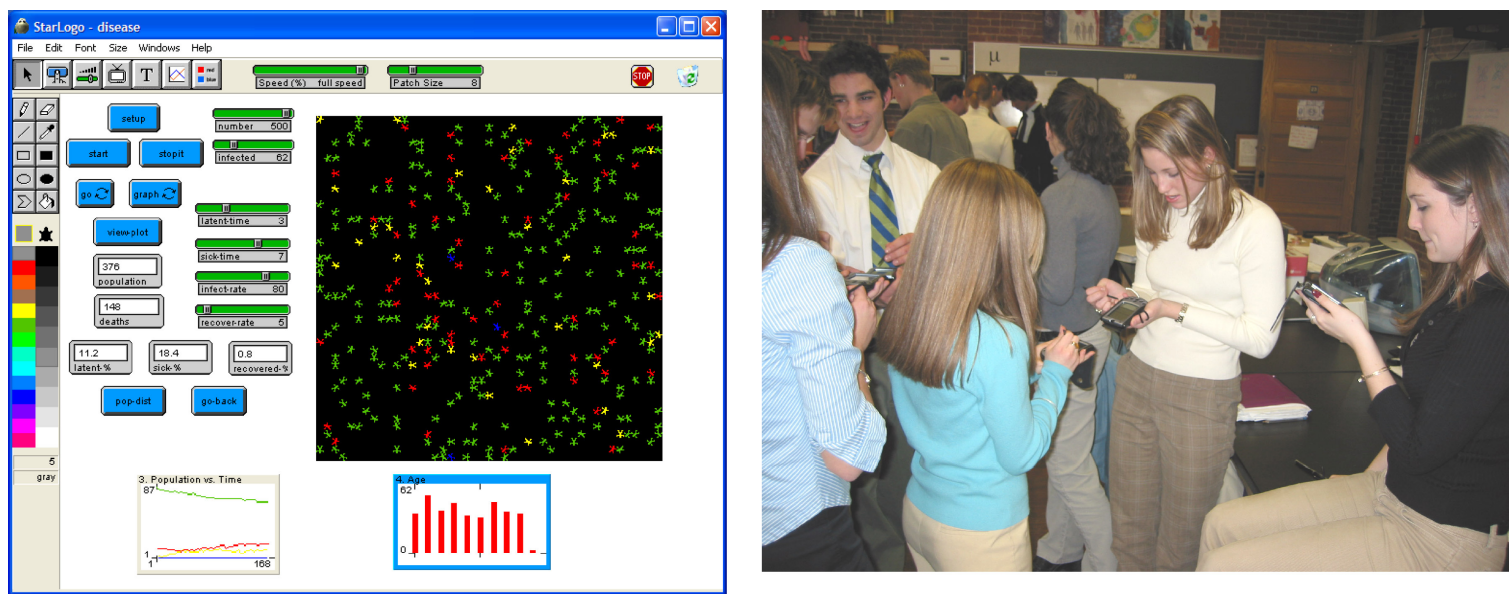

Fig. 1. The left panel shows a StarLogo model of an epidemic in action. One can see the interface area in which users can start and stop the model and adjust parameters; the running model where the different colors code for different states; and the graphs at the bottom tracking model data. The right panel shows students playing the genetics Participatory Simulation.

\section{Participants, Data Sources and Analyses}

MIT Participatory Simulation activities are implemented with a wide range of learning populations across many different geographic locations. In this study, we sought to investigate cases of teachers or instructors who represent each of the populations we work with, i.e., preservice teachers and their classes; in-service teachers in their classrooms; lead teachers or technology coordinators; teacher professional development workshop groups; and undergraduate science teaching assistants and their classes. The study questions, framework and selected data collection techniques were constructed so as to maintain as naturalistic (Lincoln and Guba, 2000) a methodology as possible. Therefore, patterns were expected to emerge from the data. Multiple data sources used for triangulation varied between teachers and groups. All categories and themes for the data set were negotiated amongst the investigator team (Strauss and Corbin, 1998). A description of the chosen teacher and/or group of teachers, their contexts, the specific Participatory Simulation use and data sources for analyses in each case is given below.

\section{Case 1: Preservice Teachers and Their Classes}

Amy and Jennifer were graduate preservice science teachers with less then 2 years practice-teaching experience who attended the same program. The two 11th-grade biology classes in which Amy ran the genetics simulation were in a low SES, high ethnically diverse public school in the Boston area. There were 19 students in each class. Amy used the genetics simulation as the organizing activity around which a genetics curriculum unit was constructed. The intention was to run it three times in the class over the course of 6 weeks; once as an introductory and culminating activity and once in the middle. Results reported here are taken from the introductory activity. By contrast, the two 10th-grade honors biology classes in which Jennifer ran the genetics simulation were in a high SES, moderately ethnically diverse school with 20 and 25 students in each class, also in the Boston area. Jennifer only used the genetics simulation once as a culminating task. Data sources for this case included written responses to three teacher surveys soliciting teaching information and pre/postimpressions of the simulation, transcriptions of follow-up audiotaped semistructured interviews using a subset of survey questions, and written in-class researcher observation field notes.

\section{Case 2: In-Service Teachers in Their Classrooms}

Henry and Peg were teachers participating in a year-long StarLogo complex systems modeling study aimed at improving students' technological and computational skills in Santa Fe and surrounding areas of New Mexico. As part of professional 
development training activities, teachers were introduced to various Participatory Simulations during a summer workshop. Henry was a second year mathematics teacher in a middle-to-low SES, moderately ethnically diverse public middle school. He ran the virus simulation in three Grade 8 math classes of varying cognitive abilities with approximately $25-30$ students in each. Peg taught general science at a progressive middle-level SES charter high school in Santa Fe. She had 7 years teaching experience. She ran the virus simulation in three Grade 9 science classes each comprised of less than 20 students. Data sources for this case included: transcribed videofootage of a professional development workshop debrief session, written email correspondence, informal teacher/researcher discussions, and postactivity questionnaires about student attitudes toward the activity.

\section{Case 3: Lead Teachers or Technology Coordinators}

John was also a teacher participant in the StarLogo study. He taught upper level mathematics in a middle to upper-middle SES public high school with low ethnic diversity. John had 9 years teaching experience. As a leader in his school, he successfully ran a professional development workshop introducing teachers to StarLogo and Participatory Simulations. This case specifically focuses on a workshop in which thirteen math and science teachers, with varying but generally low levels of technological expertise, participated. John also used the virus simulation. Data sources for this case included: transcribed videofootage of professional development activities, online teacher journal entries and pre/postprofessional development teacher surveys.

\section{Case 4: Teacher Professional Development} Workshop Groups

This case documents two professional development 1-day StarLogo workshops in which teachers in two different groups took part in Participatory Simulation activities. The first group was comprised of 16 middle- and high-school teachers recruited from public, charter and private schools in Santa $\mathrm{Fe}$ and surrounding areas. Teaching experiences of this group ranged between 0 and 41 years with a mean of 10.7 representing the subjects of social science, mathematics, biology and chemistry. They worked with the economics simulation. The second group was comprised of 24 middle and high school teachers recruited from the same area as the first group. Teaching experiences ranged between 0 and 26 years with a mean of 9.8 representing the subjects of social science, mathematics, biology, computer science and language arts. They worked with the networks simulation. ${ }^{1,3}$ Data sources for this case included transcribed video-footage of two postactivity debrief sessions with supporting information provided from other data sources such as surveys of teacher demographics, on-line teacher journals, informal discussions during workshops and e-mail communication.

\section{Case 5: Undergraduate Science Teaching} Instructors and Their Classes

Margaret was the coordinating technical instructor for an introductory undergraduate biology course at a large university. She had 7 years experience in this role. Her responsibilities included selecting teaching materials intended to augment student learning in biology lab for a group of graduate teaching instructors. Information in this case comes from a second year of implementation of the genetics simulation in which all teaching instructors were required to run the simulation once with at least two sections of undergraduate students. Data sources for this case included: video-footage of an indepth semistructured postactivity interview with the coordinating technical instructor.

\section{RESULTS}

\section{Similarities With Previous Research Findings-Handheld Computers}

\footnotetext{
The networks simulation is one of two simulations currently under construction and not listed in Table I. Netswork is an application in which players create networks by selecting a small number of people to form links with. The goal is for players to successfully send a message to a target person in the group with whom the player is not directly connected. Players must seek to understand the structure of the network as they try to find the best person to hand their message off to. Later discussion turns to how the network might be structured differently (by players choosing different people to connect to) for different purposes (e.g., redundancy, efficiency) and for understanding network characteristics more generally. Information in this case was collected from the first complete pilot run of this simulation.
} 


\section{are Engaging and Accessible}

Substantial evidence across multiple data sources yielded similar results echoing previous research evaluations of handheld activities with respect to the ability and/or likelihood of Participatory Simulations to enhance motivation, engagement and self-directed learning (cf. Colella, 2000; Vahey and Crawford, 2002). Preactivity survey responses from both teacher interns in case 1 revealed that one of the main objectives for using the genetics simulation was to provide a "hook" for students to become excited about the topic of genetics. Responses from postactivity surveys and interviews showed that after one run of the simulation with students, this objective had been met. In an answer to the question, "What benefits, if any, do you feel this educational technology tool affords to the learning process?" Jennifer writes that the activity was an "Excellent way for the students to learn the material themselves and make a complex topic very accessible." To the question "What do you think was the most successful part of today?" Amy states, "Just having fun with the game. Just the motivation and just something different and totally unique, like nothing anyone has ever done and just the excitement of that. . .trying to figure out what's going on in the game." Researcher observation field notes in the four high school classrooms indeed indicated that students were very engaged, there was "good-natured yelling," and there was " $100 \%$ engagement" even in a class that was usually quiet.

Similarly, in a summary report to the complex systems modeling cohort in one of the professional development workshops, Henry states the following:

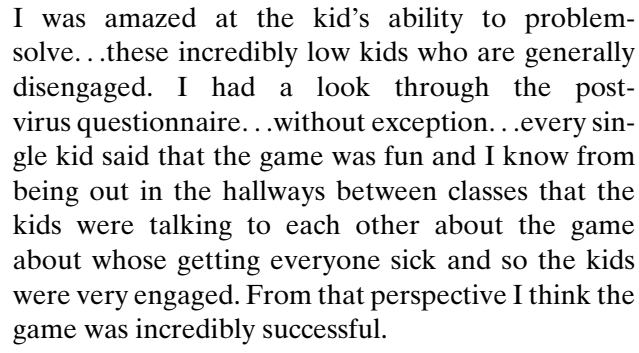

Yet, running these simulations in the classroom are also associated with real challenges. After having run through the virus simulation during John's professional development workshop in case 3 , a lengthy discussion took place amongst the more veteran teachers around the issue of teacher time constraints caused by standardized testing. Teacher 1 says:
For freshman sophomores and juniors where they have to take the test in March in their junior year where we feel that they're going to have to be looking good and we have to teach a lot more stuff because we're supposed to be including earth science that we don't have a curriculum for... and then teaching algebra 2...I'm not too clear what we're supposed to be teaching in terms of the standards. . .But I don't have a lot of time to do stuff, so, so what I've found where I'm working with AP teachers in how to do stuff, because these kinds of manipulatives and getting kids engaged is exactly what we're asking for teachers all over the country but at the same time, if we're leaving no child behind we ain't got the time to do it. .

The rest of the group nods and signals their agreement. But after a few exchanges, Teacher 2 remarks:

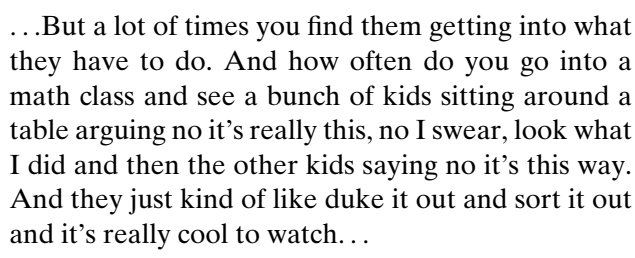

..But a lot of times you find them getting into what they have to do. And how often do you go into a math class and see a bunch of kids sitting around a table arguing no it's really this, no I swear, look what I did and then the other kids saying no it's this way. And they just kind of like duke it out and sort it out and it's really cool to watch. .

These examples demonstrate clear positive effects on student motivation, engagement and selfdirected learning from the use of Participatory Simulations. As seen in this last comment made by Teacher 2, often the perceived advantages of using this technology overcomes the battle for space in the curriculum brought on by increasing emphasis on standardized tests and the limited scope which they test. Although, no claims at this point can be made in terms of increased student motivation leading to improved standardized test scores, as Teacher 1 suggests, "getting kids engaged" is also an important educational goal that Participatory Simulations can address.

The accessibility and portability motif (cf. Soloway et al., 2001) also appeared in our data sources. For example, in a detailed email report to the principal investigator of the StarLogo study, Henry concludes:

I would definitely use the Palms in future for activities in my classroom. It is such a pleasure to have technology that works as well as not having to go through the time consuming administrative procedures to use the lab and the frustrations that go with the above On the subject of technology, I have been bugging James [principal StarLogo facilitator] for some time re: the computers in my classroom, and he came to my class on Friday. It took him (an expert) 1.5 hours to get StarLogo up and running on one of the computers, but he said that the other computer that I have been unable to fix even after more than 


\begin{abstract}
5 hours of my and another teacher's fiddling, has got various problems including CD ROM problems, so he was unable to do a repair. I am still hoping that a tech person from the district who is familiar with Mac come to my classroom.
\end{abstract}

Additional evidence supporting this theme was also found in researcher field notes taken from several on-going StarLogo workshop discussions focusing on the issue of centralized control of technology both at the district level and the local school level. At the beginning of the school year, the public school district in which a majority of our teacher participants taught, lost its technology coordinator. Teachers reported that because technological activities had been tightly controlled by the previous coordinator, there was no one in the upper echelons of administration who knew how the system operated. $\mathrm{Nu}-$ merous difficulties resulted including a dysfunctional email system and a non-functioning central district server. These problems proved to have cascading, detrimental effects on computer systems in schools. This, coupled with the fact that most computers were localized in computer labs, posed great barriers to effective computer use. Faced with lack of hardware, many of the participants decided to begin their exploration of complex systems in the classroom with their students using one or more of the handheld-based Participatory Simulations instead of desktop-based StarLogo. Since these simulations only require a nonnetworked set of Palms which can be used almost anywhere, teachers need not hassle with scheduling labs, working with poorly maintained equipment or convincing technology staff to install software.

\section{New Emergent Themes-Implementation Issues From Educators}

Further mining of the data revealed three additional themes that provide substantial insight into understanding curricular applicability of Participatory Simulations and teacher's perceptions of learning outcomes from their use. These themes generally point to the multiple layers of social and cognitive flexibility intrinsic to Participatory Simulations and suggest a different perspective on ubiquitous and accessible mobile computing:

- Ease of adaptation of subject-matter content knowledge and curricular integration

- Facility in attending to teacher-individualized goals
- Encouraging the adoption of learner-centered strategies

\section{Participatory Simulations Easily Adapt} to Subject-Matter Content Knowledge and Curricular Integration

A significant finding related to understanding curricular applicability came from professional development workshop footage in Cases 3 and 4 . In the design phase of the Participatory Simulations, the intent was to encode information about a complex system in a specific domain of knowledge, e.g., the simulation Sugar and Spice models an economic trading system. However, when this simulation was implemented at one of the StarLogo workshops teachers immediately began to make links to multiple subject areas and, although difficult to capture in a transcript of interaction, the enthusiasm felt in the room was immense. Here is an excerpt of the exchange that occurred during the activity debrief.

Teacher 1: To me it's a carbon cycle issue. I could say trees are doing. . . are basically respirating carbon dioxide into oxygen and humans the other way around and so you can say sugar and spice would be a balancing act in that sense which I realize this is going more toward commodity toward buying and selling but you can certainly also show homeostasis or stasis of one thing using one and the other thing using the other and you can maintain that for an indefinite period of time and you can show a cycle of. . .basically a carbon cycle.

Facilitator 1: Is there way that you could for kids... is there a way that you could go into this and change it to make it carbon and oxygen? Is there a way that you could get into the program?

Teacher 2: And you could have animals and plants.

Facilitator 1: Yeah that would be a good thing.

Teacher 1: Exactly

Facilitator 2: Set the labels in other words.

Teacher 3: I was thinking the way that this... with the way the game is described that pairs would go on with each other that they would just stick with each other and that would be a winning strategy...I think there are animal pairs that pair up that way cause they learn how to stay together.

Facilitator 3: I've used this in history classes with history teachers before. One of our history teachers was teaching the development of mercantilism in 
Europe and thought that would be a good time to introduce this. And it gave the kids... it very much personalized it for them.

\section{Some time later...}

Facilitator 3: One of the aspects of this, I think was most interesting is when I did this in history class. The history teacher and I talked about the notion of this being kind of a how you structure your social system kind of a game. So you could create cartels or you could have price controls imposed by a central government. So you could actually build small societies or sub-cultures in much the same way that some of you all were starting to have the pairings. You're already beginning to build small structures of society. If you did this over a number of days, you could actually explore really different organizations from that perspective.

Teacher 4: You know I was thinking as I was playing this and thinking about media. I kept thinking about looking at large multi-nationals like Vivendi merging with GE or else looking at how shoes like Nike outsource to smaller companies where it's cheaper to buy and create the materials to send them off that way. So we're going to go over to another country and trade off. So I kept thinking about the social dynamics of it more than the scientific applications.

In this footage, teachers made curricular connections to very different content domains, i.e., carbon cycle, mating strategies, development of social and cultural systems, which provides evidence for the cross-curricular value of that particular Participatory Simulation. The networks simulation likewise drew rich discussion around curricular applicability. Responses to the question, "How would you use this in the classroom," posed by the facilitator of the game yielded this excerpt:

Teacher 1: Well in core plus math we have a section dealing with networks and how to connect them dealing with the best pathway or other pathways.

Facilitator: So what grade is that?

Teacher 1: Ninth grade.

Teacher 2: And when her kids leave ninth grade and come to me in tenth grade, and we work with adjacency matrices and counting the number of paths from one to another and using the power of matrices and stuff like that and so it would fit for hers and my courses.
Facilitator: Are you guys more integrated math? Core plus is integrated math. .

Teacher 2: Now my Algebra II book has a unit on matrices and they do adjacency matrices, they don't go into the same depth as core plus but I'd bring this into that as well.

Facilitator: Other feedback...

Teacher 3: The analogy that you made about the clusters, I pictured them like two neighborhoods where you've got a lot of people knowing each other in one neighborhood. Why not just in the interface call it, I'm in the neighborhood A. Just change the name to neighborhoods instead of clusters because the game is always going to be played with people and I think the first, I mean especially with kids the first concept of network that they have is neighborhood.

Facilitator: We chose cluster because it could be a computational network as opposed to a social network or some other kind of network and so cluster is more portable but it might be that that portability is outweighed by the fact that neighborhood is more concrete.

Teacher 4: I can see this being used in many different sciences, in computer science, in any area where communication is necessary.

Teacher 5: I think that for younger kids a more explicit introductory story would be better.

Teacher 2: I would use the Pony Express, need to deliver messages between neighborhoods and their horse can only go so far.

Facilitator: So with older kids we might think about the internet.

Teacher 6: Yeah, I think with older kids it might be better to give an example of a more physical kind of network.

The teachers in this exchange related the network simulation to multiple domains of knowledge including mathematics, geography, computer science and history. It is also noteworthy that of the six teachers engaged in discussion, two were math teachers, one was a high school science teacher, one had a high school language background and one was an educational computer consultant. The mix also included middle school teachers, high school teachers and administrators all who highlighted the educational value of this simulation for a variety of educational populations. Other simulations such as Discussion (Woodruff et al., 2003) have demonstrated a similar robustness and applicability to varying forms of content. The virus simulation demonstrated 
additional potential as a a tool for fostering crosscurricular integration. The following excerpt of discussion in John's professional development session illustrates this idea:

Teacher 1: I'm thinking that there will be a number of kids excited about doing this as say a club activity or a weekend activity, you know like two or three hours every other Saturday for a few weeks. Try to give them some kind of credit where they can write some things up. You could do things with English teachers.

Teacher 2: But you're going to get a combination that's upper echelon.

John: Right, they're going to be different.

Teacher 1: Right that might be part of the issue. But part of it that's very exciting is looking at how to try to integrate the writing of the experimental methods and you bring the English teachers in where you could really start to do something that was really a holistic and synchronistic approach to the whole thing. But I don't know how you get the kids who need it...although I think all the kids need it. .

\section{Participatory Simulations Attend \\ to Teacher-Individualized Goals}

Another important theme that emerged is the flexibility built into the simulations that allow teachers to individualize curricular goals. For Peg, it was evident in footage from a workshop discussion, that the virus simulation was used to practice a form of scientific thinking with her Grade 9 science students:

John: Peg, did you make it...did you articulate specifically that they were doing the scientific process and in some way kind of explain what that was before hand?

Peg: Yup there was sort of a prethinking exercise, what is science? Or what do you know about the scientific method or process. And that was just a few minutes and then we kind of got into the role of alright as you're doing this your also making observations and so then they...we as a group broke down all the observations and then came up with question and then came up with procedures to answer the questions and that's how each round went. And it was very effective. The virus was kind of an ancillary aspect to it. It was all about the scientific process.
John: So you were real specific beforehand about what the scientific process is?

Peg: Yeah, well I didn't tell them that this is how it happens but everyone had questions and observations and everyone could ask questions and add observations to that discussion.

John: ... and that was just kind of a preactivity. It wasn't something that you had already been studying for two or three days.

Peg: No but the process...we were already getting into more lab enriched situations so they have to think about the process because they have to come up with their own procedures.

With Henry's Grade 8 math students, however, his specific interest in using Virus was geared toward demonstrating probability and exponential growth. Both Peg's and Henry's curricular goals were markedly different from each other and indeed from the original intended application of Virus toward understanding epidemiological factors in the spread of disease.

Similarly, in their preactivity questionnaires, the preservice teachers appeared to share a few similar curricular goals in introducing content specific vocabulary such as the terms heterozygous and homozygous and the concepts of mating and inheritance. However, while Jennifer elected to run the activity once as a culminating task, Amy decided to run the genetics simulation three times throughout the unit adopting the technology as a formative assessment tool. This is revealed in the following excerpt of the postactivity interview:

Amy: Exactly, and that then inheritance is related to all of those being connected. It's going to be interesting to talk about independent assortment and I mean, that's a huge topic that I think carries a lot of misconceptions and because we did this at the beginning, I can use that information to really. .

Interviewer: So you think you as the teacher got a window into the misconceptions that you might not have just doing the KWL.

Amy: We did the KWL and I did get a window into some but if students don't have an idea of the process by which inheritance works, they can't even express what they don't understand. And somehow in this game, just the mating and becoming the offspring is able to show. They can see that happening and however they attach meaning to that, you can really understand what their thinking is happening. 
In a postactivity interview about the same genetics simulation, Margaret elegantly summarizes in her view, its educational utility:

Interviewer: How did you feel this particular game or tool affects student learning?

Margaret: I think that there are several realms where this tool has implications. One is interactive group activities, "Can I learn to use the resources here to evaluate something." And that's one nongenetics thing that comes out of this. Another one is experimental design which is a great thing that the technology can do that given the standard genetics lecture is hard to communicate. Then the other one is reinforcing concepts like dominance vs. recessive and alleles and genotypes. Those are the three things. I think it's very group dependent [and] a lot depends on how much guidance the students get either from the cohort or from the person leading the activity as to how much area three gets reinforced-dominance vs. recessive, alleles, genotypes, phenotypes.

Participatory Simulations Encourage the Adoption of Learner-Centered Strategies

The last of the three emergent themes refers to the inherent nature and capacity of Participatory Simulations to encourage learner-centered instruction. In this excerpt from a postactivity interview, Amy discusses the value of the simulation in scaffolding for multiple points of entry:

Interviewer: Right, we talked about the benefits, if any...you thought it was motivating and hands-on, and obviously got kids...thinking in ways that maybe they wouldn't have otherwise in a traditional lecture format. Do you want to add anything to that about any other...

Amy: Um. . I can see where certain kids, but I didn't hear this, but it's possible certain kids maybe would have preferred to know what was happening rather than figure it out. They would have preferred someone to say that this is how the game works. Here are the rules. . you know, this is what you need to do to figure it out.

Interviewer: Some people might have been more comfortable with a little more structure...

Amy: And maybe know the terms ahead of time. But it seemed like everyone was able to engage at a different point. Like maybe it was the data table that engaged some people, maybe it was getting higher generations, getting higher points, figuring out one of the genes. There were some many different ways that different students could engage with it. Interviewer: Right, many pathways through it.

Amy: Yeah...entry points which we would call it. Multiple entry points. And that ended up I think for everyone being engaged.

Likewise, having predicted beforehand that her lower achieving students "might get lost in the chaos of the activity," Jennifer is happy to find out that this wasn't the case. In her postactivity questionnaire, she writes:

I was very pleased to see that many of my lower performing students were more engaged and had increased participation relative to my higher performing students. The higher performing students seem to enjoy having the material given to them and the other students seemed to like doing this inquirybased activity.

Moreover, in research observation field notes of the genetics simulations conducted by Amy and Jennifer, it was noted several times that students were talking to other students whom they wouldn't have otherwise talked to. The researcher also overheard a mainstream special education student say "They should let us keep it and play again," and while some students continued to engage in discussion with others about their observations, others chose to sit for a few moments with their palm computers to analyze their data screens on their own. In all of these examples, it is evident that Participatory Simulations have utility in providing a learner-centered tool to reach and engage multiple social and cognitive modalities of learning.

By revealing her initial motivation to bring handheld technology into the undergraduate biology curriculum, Margaret points out that Participatory Simulations not only serve as a great tools to encourage multiple learning but also multiple modalities of instruction. In a poignant response to the question, "What motivated you to seek out this tool for instruction," Margaret states:

Margaret: The students have lecture where somebody tells them what they need to know and they write it down and they either learn it or they don't and they have small group teaching that I design to be more interactive. I give the teaching assistants questions that are open-ended problems that they can work on with their group. But if you're a second year graduate student and the material is 
reasonably new to you and you have no background in front of an interactive group, doing something like lecturing, i.e., "let me just recap what happened in lecture," is much more comfortable then going in with a problem and saying, "well let's read this and see what we think". It's much harder to manage a group discussion than it is to act as a lecturer. And I found that although my TA's are great individuals and they're hugely interested in teaching, they're at that developmental stage where it's hard just to do group discussion. Their professional development leads them to want to tell people what's going on and their lack of development in the teaching field makes them hesitant to say, "well what do you think? Let's take this wherever it goes," because they're not sure they're going to be able to answer all the questions. So I try to come up with other things that will prevent my TA's from just lecturing. That forces the kind of dynamic learning that I imagine happens in section...that tends to happen in the sections that I lead. But that I know, my techniques, I can't hand in a basket to my TA's and have them take my tools and do it because they're different people. They're at a different developmental stage and a lot of the stuff I have developed, I find, they don't use in a way I want them to. So I wanted to give them something that they kinda had to use because it's technology-based. They can't get up in front of the class and lecture when the goal is to use this technology to discover something.

Interviewer: So what was the response from the TA's?

Margaret: It's mixed. I think they liked it. I think they liked the aspect of fun that it brought to their students.

\section{DISCUSSION}

As Roschelle and Pea (2002) accurately point out, technology-enabled learning environments are in the service and under the control of curricular regimes where the ultimate adoption and continual deployment is contingent on teacher's perceived educational utility. The goals for this study were accordingly focused on investigating teacher's perceived educational utility of the collective Participatory Simulation research program. Based on a selection of five cases that represent the kinds of educators or groups of educators with whom we work, there ap- pears to be considerable evidence indicating very favorable use. Echoing previous research with respect to the efficacy of handheld use broadly addressing domain general skills and knowledge, Participatory Simulations demonstrated positive effects in terms of student learning in the areas of motivation, engagement, self- directed learning and problem-solving. Teachers in this multiple case study also identified the ever-enduring motifs of accessibility and portability as important variables to the successful implementation of technology in the classroom in the face of great shortage and disorganization. Where the findings of this study differ however, perhaps due, in large part, to a departure in research goals from creating domain general learning tools to domain specific learning tools, is how Participatory Simulations address a ubiquity and accessibility of a different sort. In this study, teachers indicated great value for these specific handheld applications as according in three main instructional areas, i.e., ease of adaptation of subject-matter content knowledge and curricular integration; facility in attending to teacherindividualized curricular goals; and encouraging the adoption of learner-centered strategies.

The results indicated that the nature of the Participatory Simulations makes them amenable for adoption in a wide variety of domains. Teachers appropriated or hypothesized that the same technologies and ideas could be used across many subject matter areas. This may be explained by the fact that the simulations themselves are only partially enabled by the technology. Much of the way the simulation unfolds or is interpreted is set by the context in which the teacher/educator uses the simulation (Colella, 2000). While there may only be a half a dozen parameters to change in the core technology, the parameters that one can change around the technology are virtually limitless. The core systems ideas-information flow, evolution, interaction, etc., are present across many domains and may be interpreted differently in different subjects. Furthermore, the "light" technology, i.e., technology that enhances rather than drives curricular events, makes the surrounding activities flexible, and allows teachers to emphasize aspects of their curriculum that might be most appropriate for their classes, e.g., experimental design, data collection, analysis, visualization, or subject matter content.

In addition to amenability and applicability in a wide variety of domains, Participatory Simulations' function in enabling the design of learning environments also merits some discussion. 
Bransford et al. (1999) state that, decades of research on how people learn has provided instructive lessons about the design of effective learning environments. They list four interrelated and interconnected components that include: learner-centered environments - paying attention to the knowledge, skills and beliefs that the learner brings and working from the understanding that learners construct their own meanings; knowledge-centered environmentsemphasizing sense-making, constructing lessons with skills and strategies that are specific to a domain, offering ways to connect information into coherent wholes and embedding information in a context; assessment-centered environments-using formative and summative assessment strategies, using strategies that make students' thinking visible and providing opportunities for revision and feedback; and community-centered environments-connecting classrooms to larger communities, promoting collaborative learning and aligning activity goals with system norms. Based on the preceding research, we suggest that Participatory Simulations function simultaneously in all four learning environments. For example, in the scaffolding for multiple points of entry, each simulation offers a unique opportunity for learners of selectively engage in the activity based on individualized learning criteria and goals. Where Participatory simulations provide a tool for focusing specifically on the acquisition of domain-specific knowledge and that in many cases can be used to represent other very different curricular domains, knowledge-centered environments are served. In the ability for Participatory Simulations to provide information both in the formative and summative realms, assessment-centered environments are addressed. Lastly, community-centered environments are created through the on-going collaborative mode intrinsic and integral to Participatory Simulation participation. Clearly, this program of research has important implications on many educational fronts but specifically as demonstrated in this paper, for teachers who are interested in finding new and innovative methods of teaching that will serve pedagogical, content and learning goals in today's technologymediated learning environments.

\section{CONCLUSIONS}

The findings of the study contribute to previous research illustrating how Participatory Simulations engage and motivate students, and provide new evidence demonstrating the adaptive capabilities toward individual teaching and curricular goals. The next phase of investigation of Participatory Simulations will develop and explore subject-specific learning measures at the student level. While it can be argued that this phase should come early in the study due to its central importance, the evidence presented here establishes a framework for taking on this next phase as development and implementation of learning measures cannot occur until it is known how teachers use the intervention. The study revealed many different learning goals that teachers have for a given Participatory Simulation. As these different goals are identified in different contexts we can start to assess their success.

\section{ACKNOWLEDGMENTS}

We thank Eli Meir for his editorial comments on earlier manuscripts of this paper. The research in this paper was supported in part by a National Science Foundation ITEST Grant (Award \# 0322573).

\section{REFERENCES}

Abrahamson, L. A., Hantline, F., Faber, M., Robson, M., and Knapp, R. (1989). Electronic classroom system enabling interactive self-paced learning [patent \#5002491], Patent and Trademark Office, Washington DC, United States of America.

Andrews, G., Woodruff, E., MacKinnon, K. A., and Yoon, S. (2003). A preliminary report on introducing "Thinking Tags" to kindergarten students through a dental health simulation. Journal of Computer Assisted Learning 19: 209219.

Bannasch, S., and Tinker, R. (2002). Probeware takes a seat in the classroom. The Concord Consortium, Concord.ors 6(1), [Web Resource] Available Online. http://www.concord. org/newsletter/2002winter/probwre.html.

Borovoy, R., McDonald, M., Martin, F., and Resnick, M. (1996) Things that blink: Computationally augmented name tags IBM Systems Journal 35: 488-495.

Bransford, J. D., Brown, A. L., and Cocking, R. R. (Eds.). (1999). How People Learn: Brain, Mind, Experience, and School, National Academy Press, Washington, DC

Clyde, L. (2004). Computing in the palm of your hand. Teacher Librarian 31: 42-44.

Colella, V. (2000). Participatory simulations: Building collaborative understanding through immersive dynamic modeling. The Journal of the Learning Sciences 9: 471-500.

Colella, V., Klopfer, E., and Resnick, M. (2001). Adventures in Modeling: Exploring Complex, Dynamic Systems with Star Logo, Teacher College Press, New York.

Curtis, M., Luchini, K., Bobrowsky, W., Quintana, C., and Soloway, E. (2002). Handheld use in K-12: A descriptive account. In Proceedings of The First IEEE International Workshop on Wireless and Mobile Technologies in Education (WMTE'02), IEEE Press, New York, pp. 22-30.

Goldman, S., Pea, R., Maldonado, H., Martin, L., and White, T. (2004). Functioning in the Wireless Classroom. In Proceedings 
of the Third IEEE International Workshop on Wireless and Mobile Technologies in Education (WMTE'04). IEEE Press, New York.

Inkpen, K. M. (1999). Designing handheld technologies for kids. Personal Technologies Journal 3: 81-89.

Jipping, M., Dieter, S., Krikke, J., and Sandro, S. (2001). Using handlheld computers in the classroom: Laboratories and collaboration on handheld machines. (Proceedings of the 2001 SIGCSE Technical Symposium). SIGCSE Technical Bulletin 33: 169-173.

Klopfer, E., and Woodruff, E. (2002). The Impact of Distributed and Ubiquitous Computational Devices on The Collaborative Learning Environment. In Proceedings of the Annual CSCL Conference, Boulder, $\mathrm{CO}, 702$.

Klopfer, E., Yoon, S., and Rivas, L. (2004). Comparative analysis of Palm and wearable computers for Participatory Simulations. Journal of Computer Assisted Learning 20: 347359.

Lincoln, Y. S., and Guba, E. G. (2000). Paradigmatic controversies, contradictions, and emerging confluences. In Densin, N. K., and Lincoln, Y. S. (Eds.), Handbook of Qualitative Research, Sage, Thousand Oaks, CA.

May, M. (2003). Hand-on power. The Scientist 17: 1-4.

Metcalf, S and Tinker, R (2004). Probeware and handhelds in elementary and middle school science. Journal of Science Education and Technology 13: 43-49.

Ogata, H., Yano, Y., Furugori, N., and Jin, Q. (2001). Computer supported social networking for augmenting cooperation, computer supported cooperative work. The Journal of Collaborative Computing 10: 189-209.

Ogata, H., and Yano, Y. (2003). How ubiquitous computing can support language learning, In Proceedings of KEST 2003, Honjo, Akita, Japan, 1-6.

Relan, A., Guiton, G., Parker, N., and Wilkerson, L. (2003, April). A Hand-Held Requirement for Clinical Education: Effectiveness of a Systemic Educational Intervention in Altering Perception and Use of Handhelds Among Medical Students. Paper presented at the annual meeting of the American Educational Research Association, Chicago, IL
Resnick, M. (1994). Turtles, Termites and Traffic Jams: Explorations in Massively Parallel Microworlds, MIT Press, Cambridge, MA

Roschelle, J., and Pea, R. (2002). To Unlock the Learning Value of Wireless Mobile Devices, Understand Coupling. In Proceedings of the IEEE International Workshop on Wireless and Mobile Technologies in Education (WMTE'02).

Roschelle, J. (2003). Unlocking the learning value of wireless mobile devices. Journal of Computer Assisted Learning 19: 260272

Soloway, E., Norris, C., Blumenfeld, P., Fishman, B., Krajcik, J., and Marx, R. (2001). Handheld devices are ready-at-hand. Communications of the ACM 44: 15-20.

Strauss, A. L., and Corbin, J. M. (1998). Basics of Qualitative Research: Techniques and Procedures for Developing Grounded Theory (2nd ed.), Sage, Newbury Park, CA.

Tinker, R., and Krajcik, J. (2001). Portable Technologies: Science Learning in Context, Kluwer Academic, New York.

Vahey, P., and Crawford, V. (2002). Palm Education Pioneers Program: Final Evaluation Report, SRI International, Menlo Park, CA.

Wilensky, U., and Stroup, W. (2000). Networked Gridlock: Students Enacting Complex Dynamic Phenomena with the HubNet Architecture. In Proceedings of The Fourth Annual International Conference of the Learning Sciences, Ann Arbor, MI.

Woodruff, E., Klopfer, E., Yoon, S., and Young, L. (2003). Platforms for Participatory Simulations: Generating Discourse with Wearable and Handheld Computers. In Proceedings of the Computer Supported Collaborative Learning annual conference, Bergen, Norway.

Yoon, S., and Woodruff, E. (2003, April). Rethinking Teaching and Learning About Scientific and Technological Issues: Exploring the Development of Memes in a Complex System. Paper presented at the annual meeting of the American Educational Research Association, Chicago, IL.

Zurita, G., and Nussbaum, M. (2004). Computer supported collaborative learning using wirelessly interconnected handheld computers. Computers and Education 42: 289-314. 